\title{
Pedagogías sentipensantes y revolucionarias en la praxis educativo-política de los movimientos sociales de América Latina
}

Sensing/Thinking and Revolutionary

Pedagogies in the Educational and Political

Praxis of Social Movements in Latin America

Pedagogias Sentipensantes e Revolucionárias na práxis educativo-política dos movimentos sociais na América Latina

\author{
Lia Pinheiro-Barbosa* iD orcid.org/0000-0003-0727-9027
}

Para citar este artículo: Pinheiro-Barbosa, L. (2020). Pedagogías sentipensantes y revolucionarias en la praxis educativo-política de los movimientos sociales de América Latina. Revista Colombiana de Educación, I(80), 269-290. https://doi.org/10.17227/rce.num80-10794

(c) $)(1) \Theta$

Recibido: $27 / 11 / 2019$

Evaluado: 29/03/2020

* Doctora en Estudios Latinoamericanos por la Universidad Nacional Autónoma de México (UNAM). Docente en la Universidade Estadual do Ceará (UECE), en el Programa de Pós-Graduação em Sociologia (PPCS) y en el Mestrado Acadêmico Intercampi em Educação e Ensino (MAIE), Brasil. 


\begin{abstract}
Resumen
El presente artículo de revisión tiene por objetivo plantear elementos teóricos y metodológicos para pensar el campo problemático que articula la relación entre procesos históricos de resistencia, educación y conocimiento en la conformación de pedagogías sentipensantes y revolucionarias en la praxis educativo-política de los movimientos indígenas y campesinos de América Latina. En esa dirección, al afirmar la existencia de un carácter revolucionario y sentipensante en la praxis pedagógica de los movimientos, recupero el debate teórico-político de la teoría crítica, en Frantz Fanon Orlando Fals-Borda y Silvia Rivera Cusicanqui, y del pensamiento pedagógico latinoamericano, en Paulo Freire y Carlos Mariátegui, en el sentido de identificar al sujeto revolucionario de Latinoamérica en los diferentes periodos históricos de tensionamiento en la disputa hegemónica. En esos procesos de disputa de hegemonía, la región latinoamericana demarca especificidades históricas que entretejen las concepciones de lo educativo y de lo pedagógico, en el sentido de situar qué es lo que constituye un proyecto de educación en la perspectiva de los movimientos indígenas y campesinos de la región, quiénes son los sujetos de la educación, a qué discursos educativos y a cuáles intencionalidades socioculturales y políticas responden. Asimismo, el artículo plantea algunos ejes metodológicos para interpretar los elementos que estructuran la concepción de lo educativo y de lo pedagógico en los proyectos educativo-políticos de los movimientos indígenas y campesinos, acompañados de ejemplos concretos de las experiencias educativas en curso: la dimensión epistémica (el ethos, proyecto ético-político y valores), lo procedimental (estrategias, saberes y sujetos) y lo pedagógico.
\end{abstract}

\section{Palabras clave}

pedagogías emancipatorias; movimientos indígenas y campesinos; educación; praxis política

\section{Keywords}

emancipatory pedagogies; indigenous and peasant movements; education; political praxis
This review article aims to raise theoretical and methodological elements to thint about the problematic field that articulares the relationship between historica processes of resistance, education and knowledge in the formation of sentipensante and revolutionary pedagogies in the educational-political praxis of indigenous and peasant movements in Latin America. In this direction, by affirming the existence of a revolutionary and sentipensante character in the pedagogical praxis of the movements, I recover the theoretical-political debate of critical theory in Frantz Fanon, Orlando Fals-Borda and Silvia Rivera Cusicanqui, and of Latin American pedagogical thought, in Paulo Freire and Carlos Mariátegui, in the sense of identifying the revolutionary subject of Latin America in the different historical periods of tension in the hegemonic dispute. In these processes of dispute over hegemony, the Latin American region demarcates historical specificities that interweave conceptions of education and of pedagogy, in the sense of situating what constitutes an education project within the perspective of indigenous and rural movements of the region, who are the subjects of education, to what educational discourses, and to what socio-cultural and political intentions they respond. Likewise, the article proposes some methodological axes to interpret the elements that structure the conception of education and pedagogy in the educational-political projects of the indigenous and rural movements, accompanied by concrete examples of current educational experiences: the epistemic dimension (the ethos, ethical-political project and values), the processual (strategies, knowledge and

\section{Resumo}

Este artigo de revisão visa apresentar elementos teóricos e metodológicos para pensar o campo problemático que articula a relação entre processos históricos de resistência, educação e conhecimento na formação de pedagogias sentipensantes e revolucionárias na práxis educativo-política dos movimentos indígenas e camponeses na América Latina. Neste sentido, ao afirmar a existência de um carácter revolucionário e sentipensante na práxis pedagógica dos movimentos, recupero o debate teórico-político da teoria crítica, em Frantz Fanon, Orlando Fals-Borda e Silvia Rivera Cusicanqui, e do pensamento pedagógico latino-americano, em Paulo Freire e Carlos Mariátegui, no sentido de identificar o sujeito revolucionário da América Latina nos diferentes períodos históricos de tensão na disputa hegemônica. Nestes processos de disputa de hegemonia, a região latino-americana demarca especificidades históricas que entrelaçam concepções de educação e de pedagogia, no sentido de situar o que constitui um projeto educativo na perspectiva dos movimentos indígenas e campesinos da região, quais são os sujeitos da educação, a que discursos educativos, e a quais intencionalidades socioculturais e políticas respondem. O artigo propõe, ainda, alguns eixos metodológicos para interpretar os elementos que estruturam a concepção do educativo e do pedagógico nos projetos educativo-políticos dos movimentos indígenas e camponeses, acompanhados de exemplos concretos de experiências educativas em: a dimensão epistêmica (o ethos, o projeto ético-político e valores), o procedimental (estratégias, saberes e sujeitos) e o pedagógico.

\section{Palavras-chave}

pedagogias emancipatórias; movimentos indígenas e camponeses; educação; práxis política 


\section{Introducción}

En el escrito presento algunos elementos de carácter conceptual y metodológico para pensar el campo problemático que articula la relación entre procesos históricos de resistencia, educación y conocimiento en la conformación de pedagogías sentipensantes y revolucionarias en América Latina. Para ello, sitúo el lugar de inscripción de la memoria histórica en la concepción de lo educativo y de lo pedagógico en el ámbito de la praxis política de los movimientos sociales latinoamericanos, en particular, de los movimientos indígenas y campesinos, y cuáles elementos aportan a la proposición y consolidación de proyectos educativo-políticos para un devenir emancipatorio.

Los proyectos educativo-pedagógicos articulados por estos movimientos parten de tres premisas: (1) Construir un proceso educativo que promueva la ruptura con la dialéctica de la opresión, de carácter colonial, patriarcal, racista y clasista; (2) El vínculo con una crítica onto-epistémica a la imposición del paradigma civilizatorio occidental moderno eurocéntrico capitalista como alma mater y canon interpretativo del mundo y de las relaciones socioculturales, de producción y política; y (3) Constitutivo de una disputa hegemónica en cuanto fuerza social e histórica, en que se conciba la praxis educativo-pedagógica como un proyecto de hegemonía, lo que requiere la génesis de una nueva cultura política que responda a los desafíos de la crisis civilizatoria (Barbosa, 2015). La disputa hegemónica implica la capacidad de articular, en el campo popular, una reflexión crítica con respecto a los procesos de dominación histórica en la relación sociedad-Estado, a la vez que preconiza la proposición de un proyecto político que estimule la conformación de una conciencia de clase y la génesis de una nueva cultura política, condición sine qua non para la consolidación de una dirección política hacia un proyecto de carácter emancipatorio (Gramsci, 1975).

En esos procesos de disputa de hegemonía, la región latinoamericana demarca especificidades históricas que entretejen las concepciones de lo educativo y de lo pedagógico, en el sentido de situar qué es lo que constituye un proyecto de educación en la perspectiva de los movimientos indígenas y campesinos de la región, quiénes son los sujetos de la educación, a qué discursos educativos y a cuáles intencionalidades socioculturales y políticas responden. En esa dirección, al afirmar la existencia de un carácter revolucionario y sentipensante en la praxis pedagógica de los movimientos, recupero el debate teórico-político del pensamiento crítico latinoamericano, en el sentido de identificar al sujeto revolucionario de Latinoamérica en los diferentes periodos históricos de tensionamiento en la disputa hegemónica. En esa dirección, coincido con Mariátegui (1928) con respecto a la existencia de un potencial sujeto

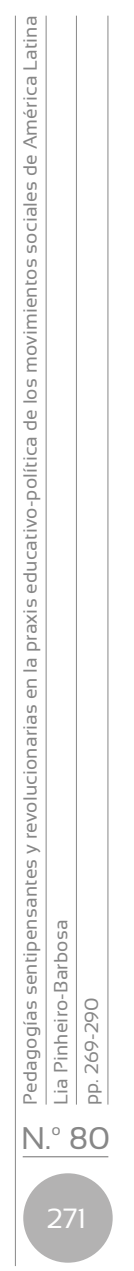


revolucionario en América Latina, representado por los pueblos originarios, a la vez que sostengo que, en nuestro tiempo histórico, este sujeto revolucionario se alarga, una vez que incorpora al campesinado en un sentido más amplio, es decir, de los pueblos del campo que utilizan la tierra para la reproducción de la vida (Silva, 2014). Ambos impulsan proyectos políticos en los que la educación ejerce un papel central en la conformación de sujetos histórico-políticos de disputa hegemónica en el campo latinoamericano.

Asimismo, destaco el lugar de inscripción de la categoría Sentipensante en ese debate, conforme al análisis de Fals-Borda (2009), una traducción categórica del corazón como núcleo de una racionalidad propia de las epistemologías y de las ontologías de los pueblos de América Latina. Esta categoría fue recuperada por él en su experiencia junto a los pueblos ribereños de la costa Atlántica de Colombia. Los seres humanos sentipensantes son aquellos que combinan el corazón y el cuerpo, la razón y el sentimiento en la concepción e interpretación del mundo y de las interrelaciones entre humanos, no humanos y naturaleza en una perspectiva pluriversa, proceso histórico que incide en la producción de conocimiento y en el intercambio de saberes intrínsecamente vinculados a sus formas de vida y lucha.

Con base en ello, el artículo analiza los elementos constitutivos de las pedagogías sentipensantes y revolucionarias en la praxis educativo-política de los movimientos sociales latinoamericanos, organizándose en cuatro sesiones: la primera se destina a contextualizar particularidades del proceso histórico latinoamericano que inciden directamente en las subjetividades políticas de la resistencia del campo popular, especialmente a lo largo del siglo xx y en el nuevo siglo, periodo histórico de donde emana una concepción propia de proyecto educativo por parte de los movimientos sociales. Enseguida, destacaré los elementos que configuran la identidad política de los movimientos sociales en Latinoamérica y su incidencia en la elaboración de una concepción de educación y de pedagogía. En la tercera sesión me adentro en lo que Ilamo pedagogías sentipensantes y revolucionarias, planteando elementos de orden teórico y metodológico que sostienen las interrelaciones entre educación, resistencia y conocimiento en el horizonte político de un proceso emancipatorio erigido desde la praxis educativo-política de los movimientos sociales de América Latina.

Por último, presentaré los aprendizajes de estas pedagogías sentipensantes y revolucionarias, especialmente en la consolidación de concepciones propias de lo educativo, de lo pedagógico y la construcción de conocimiento desde/con/para los movimientos sociales de América Latina. 


\section{Del Abya Yala a la América Latina indígena, negra, campesina y popular}

La formación sociocultural, política y económica de Latinoamérica tiene raíces en las colonizaciones de los territorios del Abya Yala, caracterizadas por matrices de orden patriarcal, colonial y racista, en la consolidación del latifundio y del sistema esclavista como matriz productiva, cultural y política, elementos constitutivos que ejercieron influencia en la naturaleza de los Estados nacionales, en las relaciones socioculturales, en las diferentes fases de desarrollo de las fuerzas productivas y de las relaciones de producción en la región, hasta culminar en la actual etapa de desarrollo del capitalismo, de corte transnacional y dependiente (González-Casanova, 1969).

Esas matrices originaron una profunda segregación social y un antagonismo de clase determinados, por un lado, por la condición estructural de quienes (no) detentan los medios de producción y, por el otro, por el lugar social atribuido por los conquistadores (y por las élites nacionales poscolonización) a los pueblos originarios, los afrodescendientes y los campesinos (que en la mayoría de los países latinoamericanos descienden de los dos primeros).

Frente a una exclusión social históricamente instituida, emergen en el movimiento dialéctico de la historia social procesos de resistencia articulados por los pueblos de América Latina en el campo y en la ciudad. En un marco histórico más amplio, en los diferentes países de la región las rebeliones populares y los movimientos independentistas a finales del siglo xix e inicios del xx abrieron camino a la conformación de las primeras repúblicas, sentando las bases de una concepción germinal de derechos y de ciudadanía, con la intención de que fuera incorporada a los nacientes Estados nacionales. El siglo xx retoma la noción más amplia de derechos, tornándose escenario de procesos históricos importantes, de carácter popular y revolucionario, con el objetivo de plasmar, en los marcos jurídico-legales y constitucionales, los derechos humanos, civiles y políticos para los pueblos originarios, las poblaciones campesinas y afrodescendientes, en definitiva, las que históricamente fueron expropiadas de sus territorios y sometidas a una condición de dominación y subordinación.

En ese registro histórico, las revoluciones de Haití y de México inauguran las grandes revoluciones de carácter popular de América Latina en la transición del siglo xIx al Xx. Luego, están aquellas lideradas por movimientos de liberación nacional, clandestinos y de guerrilla armada, que culminaron en movimientos como la Revolución Cubana, en 1959, y la Revolución Sandinista en Nicaragua, en 1979. Las consignas políticas

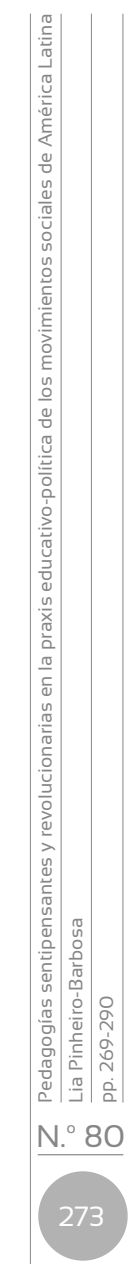


de esas revoluciones recuperaban la denuncia histórica del latifundio en el proceso de expropiación territorial y en la paulatina subalternización de los pueblos originarios y campesinos. La reivindicación del derecho a la tierra y la realización de la reforma agraria constituían la base del proyecto nacional-popular. Pese las diferencias y especificidades con respecto a la concepción teórica del proceso revolucionario y las estrategias internas de lucha, un elemento común de esas revoluciones era el anhelo por construir un proyecto emancipatorio de base popular y articulado por sujetos histórico-políticos del campo y de la ciudad.

El ciclo de las revoluciones de América Latina y del Caribe desencadenó procesos políticos de relieve, tanto en el ámbito interno de cada país, como también en perspectiva regional. Desde el punto de vista de una reforma intelectual y moral (Gramsci, 1968) paulatinamente se concretó el ideario de Simón Bolívar y de José Martí, en el sentido de consolidar un pensamiento social latinoamericano y caribeño, y una praxis política revolucionaria, polinizados por referentes de las luchas históricas trabadas en los contextos nacionales, pero igualmente inspiradas por aquellas de carácter internacional.

En el campo educativo, estos procesos pusieron en el eje del debate político la centralidad de lo educativo y de lo pedagógico en la formación del sujeto revolucionario y en la urgencia histórica por proponer un proyecto educativo capaz de erradicar el analfabetismo y promover el acceso universal a la educación formal en todos los niveles. La concepción política del proyecto educativo auspiciado por estos procesos revolucionarios se inspiraba en las pedagogías soviéticas, a la vez que se fortalecía en los principios martinianos y de la educación popular. En paralelo a los procesos revolucionarios, otra parte del campo popular seguía el curso de la resistencia histórica en otros contextos nacionales, algunos de ellos bajo el yugo de gobiernos dictatoriales militares, y asumía una posición histórica como potenciales sujetos revolucionarios. Tal es el caso de la resistencia histórica construida por los pueblos originarios, campesinos, afrodescendientes y la clase trabajadora del campo y de la ciudad de Mesoamérica, de los países andinos y del Cono Sur.

Al final del siglo xx, la agudización de las contradicciones sociales y político-económicas resultantes de la implementación de las medidas neoliberales y posdictatoriales hizo eclosionar un nuevo ciclo de luchas en América Latina. La lucha de clases permanecía como brújula en el enfrentamiento político-ideológico del neoliberalismo y de la transnacionalización del capital, sobre todo con el capitalismo agrario. No obstante, la memoria histórica de la resistencia popular se mantenía viva, latente y era enriquecida por otros elementos de carácter histórico, como la lucha anticolonial, muy presente en el ámbito de los discursos y de los documentos políticos de los movimientos populares, a propósito de la 
denuncia histórica de las relaciones coloniales que se erigieron bajo la categoría raza y los signos de opresión derivados de ella para los pueblos originarios y campesinos.

Un factor determinante en la lucha anticolonial de ese periodo fueron las celebraciones del Quinto Centenario, convocadas por España y jefes de Estado de los países de la región. En respuesta, el campo popular articuló la Campaña Continental por el Autodescubrimiento de Nuestra América, organizada por movimientos indígenas de toda Latinoamérica. Asimismo, la Campaña 500 Años de Resistencia Indígena, Negra y Popular (1989-1992) congregó las más diversas organizaciones del campo popular en la denuncia de la carga histórica de la Conquista en el avasallamiento, la opresión y la discriminación hacia los pueblos originarios, afrodescendientes y campesinos. Dichas campañas permitieron consolidar una articulación regional entre el conjunto de organizaciones campesinas, indígenas, afrodescendientes y de trabajadores rurales para pensar una estrategia política transnacional en la defensa de los territorios y de un proyecto anticolonial, antisistémico y anticapitalista.

De ahí que al final del siglo xx y en los umbrales del xxl, vemos emerger movimientos emblemáticos, como el Movimiento de los Trabajadores Rurales Sin Tierra (MST), en Brasil, la insurgencia armada del Ejército Zapatista de Liberación Nacional (EZLN), en México, las guerras que se llevaron a cabo en Bolivia, a propósito de la Guerra del Gas y la Guerra del Agua articuladas por los movimientos indígenas, además de la conformación de La Vía Campesina Internacional (LVC) y de la Coordinadora Latinoamericana de Organizaciones del Campo (ClOC), instancias de articulación de las organizaciones populares y los movimientos sociales indígenas y campesinos en las escalas internacional y regional, respectivamente (Barbosa, 2015; Gutiérrez-Aguilar, 2008; Martínez-Torres y Rosset, 2013). Otros hitos importantes se destacan en ese periodo, como las múltiples rebeliones indígenas en Ecuador (en los decenios de 1980 y 1990), el Caracazo (1989) en Venezuela y la reacción popular en contra del neoliberalismo en Argentina (2001). En ese debate regional, permanecía la problemática histórica común, relacionada con el permanente despojo territorial y con una violencia institucional del Estado, de carácter colonial y racista, que se expresaba en la criminalización de las luchas populares y en el incremento de la violencia en el campo.

Se ponía en pugna a la modernidad histórica que, en realidad, expresaba la esclavitud de los pueblos y la negación de su existencia como sujetos histórico-políticos (Cusicanqui, 1986). Esa modernidad era considerada cuna del racismo colonial; de la introyección, en el inconsciente colectivo, del mito de que el no blanco es, por definición, el malo, raíz del complejo de dependencia del colonizado. Es decir, la inferiorización como correlato nativo de la superiorización europea (Fanon, 2008).

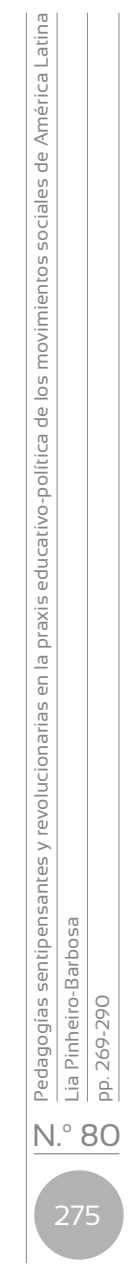


Frente a esa negación histórica, era imprescindible reivindicar el rostro negado de América Latina (indígena, negra y campesina), es decir, no solo el derecho de existir, sino también de ser y de enfrentar el peso histórico de ser nombrados como los otros. Asimismo, en ese caudal del campo popular, la reivindicación política del Abya Yala, en el marco de la ॥ Cumbre Continental de los Pueblos y Nacionalidades Indígenas del Abya Yala, realizada en Quito, en el 2004, demarcaba a los pueblos originarios como sujetos enunciadores de un discurso político desde otros referentes en la disputa hegemónica de los territorios (Porto-Gonçalves, 2009). Entra en escena un sujeto histórico y una concepción de praxis política que reconfigura el campo de disputa hegemónica. Asimismo, algunos elementos estructuran la identidad política de los movimientos indígenas y campesinos latinoamericanos.

\section{Identidad política}

Herederos de esa resistencia histórica, los movimientos indígenas y campesinos tejen su identidad y praxis políticas en un proceso continuo de recuperación de la memoria histórica de las luchas que se llevaron a cabo en otros momentos de la resistencia latinoamericana y caribeña. Por lo tanto, la identidad política de esos movimientos no se limita a los elementos constitutivos de la izquierda internacional, es decir, a los principios que fundamentan el comunismo y el socialismo como horizontes políticos.

Sin necesariamente negarlos o contradecirlos, los movimientos indígenas y campesinos amplían los referentes que les adjudican una identidad política, al demarcar que son parte de un movimiento forjado en más de cinco siglos de historia. En ese proceso de auto-definición de una identidad política, las organizaciones populares y los movimientos indígenas y campesinos de Latinoamérica se agrupan en tres categorías, definidas a partir de epistemes propias y que articulan marcos identitarios vinculados a sus luchas políticas (Barbosa y Rosset, 2017; Rosset; 2015): de identidad indígena; de identidad campesina y de identidad proletaria rural. Con respecto a la unidad de la lucha latinoamericana articulada por ellas, identificamos, por lo menos, cuatro ejes de identidad política (Barbosa, 2013), que se presentan a continuación.

1. Reconfiguración de la historia y de la memoria en el marco de las luchas: los movimientos indígenas y campesinos no conciben la historia tan solo en una perspectiva lineal, sino en ciclos espirales. Pensar la historia en ciclos les permite, por un lado, interpretar la memoria colectiva larga, marcada por hitos, herencias simbólicas, figuras que expresan la permanente violencia colonial sobre los cuerpos, las creencias y los conocimientos de los pueblos, y por otro, fortalecer 
las memorias colectivas cortas, en las que se conectan, coexisten y antagonizan con el horizonte colonial. Esa concepción de la historia, del tiempo y de la memoria se asemeja al concepto aimara ñawpaj manpuni, que se refiere a un "mirar hacia atrás que también es un ir hacia adelante" (Cusicanqui, 1986), es decir, retomar el pasado con una proyección de futuro que se conjuga en el presente del proceso de resistencia política.

2. Dimensiones epistémica y ontológica que emanan de las cosmovisiones y sostienen las bases de una racionalidad ancestral, que se configura desde una matriz cosmogónica, lingüística y sociocultural milenaria. Esa dimensión onto-epistémica fundamenta a las subjetividades políticas de estos movimientos, su concepción del tiempo, de la vida y de la muerte, de su posicionamiento (individual y colectivo) en el mundo y una interpretación del ser humano como una fracción de la totalidad de la vida existente en la naturaleza. Entre los varios referentes de matriz onto-epistémica cito algunos, por ejemplo, el Lekil Kuxlejal, de la lengua maya, el Sumak Kawsai (del quechua ecuatoriano) o Sumak Qamaña (del aimara boliviano) o buen vivir, comprendido como principio esencial de los derechos humanos y de la naturaleza, en contraposición a la perspectiva del "vivir mejor" defendido por el capitalismo moderno. Otra instancia de la dimensión epistémica la constituye la matriz lingüística de las lenguas originarias, que determinan otras posiciones de sujeto y de pensamiento, al conferir horizontalidad entre el yo-nosotros-comunidad y la mente-corazón-espíritu (Lenkersdorf, 2005; López-Intzín, 2013).

3. Territorialidad. El territorio es el locus de re-existencia de los pueblos y de conformación de un ethos, parte constitutiva de la narrativa política de los movimientos indígenas y campesinos, en la defensa de la tierra, de la naturaleza y de los comunes. El territorio también involucra los procesos de territorialización, momento de aprehensión y de construcción de identidades para los pueblos, de los modos de ser, de estar y de coexistir. El Tawantinsuyu, el Wallmapu - para citar algunos referentes- constituyen una concepción del territorio como espacio de vida, en una relación permanente entre el cosmos, las colectividades humanas, no humanas y el entorno natural en que viven. Más allá de una perspectiva antropocéntrica, esa relación otorga al territorio un simbolismo y una ritualidad complejos, en el reconocimiento de su vitalidad, de los sentidos de la producción, de creación y re-significación de las relaciones socioculturales y de poder. Por esta razón, el territorio cobra particular relevancia frente a los conflictos inherentes a la disputa del capital transnacional por la vía de las minerías, del

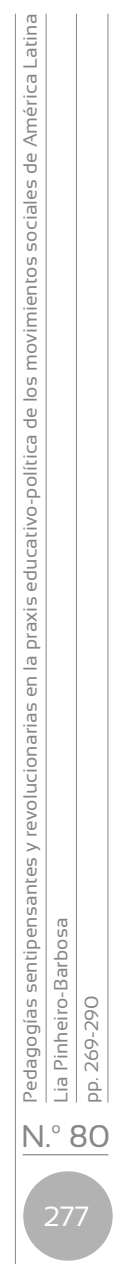


agronegocio, entre otros megaemprendimientos en los territorios latinoamericanos (Giacarra, 2006; Svampa y Antonelli, 2009). Al interpelar la concepción de territorio desde el paradigma de desarrollo moderno occidental capitalista, los movimientos indígenas y campesinos ponen en movimiento ontologías relacionales (Escobar, 2014) y reivindican el reconocimiento de una lógica pluriversa de concebir y habitar el territorio.

4. Autonomía. Comprendida como principio y proyecto político para muchos movimientos indígenas, se concibe en un vínculo con las dimensiones epistémica y ontológica de la cosmovisión, del principio de la comunalidad, y de un sentimiento de pertenencia territorial que son preexistentes a la conformación del Estado-nación como instancia institucional, de regulación social y de representación política. Tiene que ver con la reivindicación del derecho de autodeterminación de los pueblos en sus territorios, que es parte de las tradiciones comunales, de las formas históricas de deliberación y participación política articuladas por comunidades organizadas en torno a la vida comunitaria en sus territorios, anteriores a la Conquista (González et al., 2010; Mariátegui, 1928; Tapia, 2006).

Estos cuatro ejes perfilan la naturaleza de las demandas y la concepción de proyectos políticos llevados a cabo por estos movimientos. Asimismo, han nutrido las estrategias de lucha, entre ellas aquellas relacionadas con el campo educativo-pedagógico, contexto en que emergen otras concepciones de educación y de pedagogía para la conformación del sujeto histórico-político (Barbosa, 2013, 2015), conforme plantearé a continuación.

\section{Pedagogías sentipensantes y revolucionarias en América Latina}

A partir de lo expuesto, se observa que, en el contexto de conformación de una propuesta política desde el campo popular, los movimientos indígenas y campesinos incorporaron el debate educativo como instancia imprescindible para la formación de un sujeto político en cuanto fuerza histórica para la conducción de las tácticas y estrategias inherentes a la disputa hegemónica. La conformación de un proyecto educativo incorporó referentes de la memoria histórica, de la teoría política y de las pedagogías críticas para un devenir emancipatorio. En la perspectiva de estos movimientos, la concepción de un horizonte emancipatorio tiene que ver, a priori, con la superación de la dialéctica del colonialismo, del racismo, del patriarcado y del antagonismo de clase, bases de la formación sociocultural y política de América Latina. 
En otros términos, que la educación propicie elementos para una comprensión crítica de esa totalidad histórica y articulada a procesos de liberación y descolonización (Fanon, 2005; Freire, 1987). La conformación de una conciencia crítica para una transformación social emancipadora se vincula a la aprehensión de las categorías Oprimido y Libertad en los términos de Freire (1987) y Fanon (2005). Invocar a la "libertad" representaba liberarse de un complejo de dominación política, económica y cultural heredada desde los tiempos de la Conquista, y las relaciones establecidas con las oligarquías agrarias y esclavistas, las burguesías transnacionales, sujetos de imposición, hasta nuestros días, de la dominación simbólica, ideológica y material. El proceso de liberación es de tipo histórico, cultural y político, de la lucha de clases, de la disputa hegemónica sea por la vía institucional —en la reivindicación de la dimensión pública del Estado- sea por la no institucional, en la construcción de espacios de poder no estatal, de carácter comunitario y autónomo (Barbosa, 2010).

En el contexto de la lucha de los pueblos originarios y del campesinado, la liberación camina a la par de los procesos históricos de descolonización y de despatriarcalización. La descolonización, a su vez, no se limita a un reconocimiento de lo identitario y de conquista de derechos en el orden del capitalismo, sino que se enfoca en el encuentro profundo entre dos fuerzas congénitamente antagónicas, que les permita situarla como cuestionamiento integral de la situación colonial y de la violencia inherente a ella; la transformación del ser que pasa por una ruptura con los esquemas psíquicos de interiorización del opresor (Fanon, 2005), el autorreconocimiento en cuanto sujeto histórico, con capacidad de elaboración teórica anclada en una vivencia sociopolítica que le adjudica una autoridad epistémica para plantear propuestas concretas articuladas a la necesidad de superación de las estructuras que permiten la reproducción de la dominación y de la subalternización capitalista occidental moderna.

Al descolonizar los pensamientos y los cuerpos, se reivindican otras formas de ser y de posicionarse social y políticamente, desde las cosmovisiones y el ethos con el territorio, en la comprensión crítica de que el proceso de conformación de una identidad política se constituye a partir de una memoria histórica, de formas de organización social de carácter comunitario y colectivo, de otros paradigmas de conocimiento que, si bien pueden dialogar con el paradigma occidental moderno, no son inferiores a este con respecto a los horizontes de interpretación histórica y de transformación social. Por ello, se vuelve fundamental concebir el acto educativo como momento de aprehensión del proceso social en su totalidad histórica, en una objetivación del mundo y de enfrentamiento de la realidad social concreta. Es decir, una conciencia

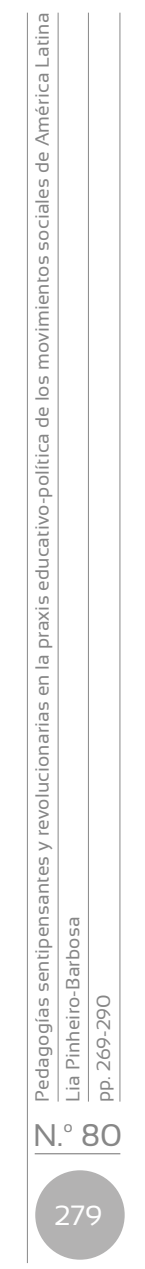


crítica que brota de la praxis del ser humano como creación autónoma, libre, creativa; de fortalecimiento de un sujeto histórico-político y de construcción de un camino hacia la liberación y la emancipación humana (Freire, 1987).

En la lectura cuidadosa de su realidad pasada y presente, muchos movimientos identifican la siguiente cuestión: si la educación constituyó el punto de partida en la inferiorización subjetiva, en la subordinación cultural y en la dominación política, será en la construcción de otra concepción de educación (que implica otra pedagogía, otra escuela, otro currículo, otro sujeto pedagógico) donde se dará el primer paso para un proceso de liberación, de descolonización y de emancipación. En esa dirección, han desarrollado una discusión interna que les permitió situar el plan epistémico como idea central en la concepción de la educación y de la pedagogía, enfatizándolas como eje medular, el corazón de sus proyectos políticos. Para ello, avanzan paulatinamente en la relación dialéctica conocimiento como poder-conocimiento con poder (Torres-Méndez, 2013) para asumir su propio caminar histórico-político.

Entre los fundamentos teórico-políticos de la concepción de lo educativo y de lo pedagógico en la perspectiva de los movimientos indígenas y campesinos se destacan el legado de la educación popular, de la teología de la liberación, del pensamiento pedagógico latinoamericano y de la pedagogía socialista. Asimismo, han incorporado otros elementos de las bases de su identidad política (la memoria histórica, la cosmovisión, el territorio, la autonomía) y que son intrínsecos a las filosofías indígenas, a los referentes epistémicos y ontológicos de la cosmogonía y de las matrices lingüísticas originarias, responsables por atribuir un carácter genuino a los procesos educativo-políticos por ellos formulados.

De ahí que en América Latina se materializan proyectos educativo-políticos de relieve, que conforman un sujeto histórico-político, conceptos teórico-epistémicos propios y experiencias pedagógicas que ponen en movimiento la concepción misma de educación, de pedagogía y de escuela. Entre estas experiencias, destaco algunas de mayor relieve regional:

» La Educación del Campo, las escuelas itinerantes y la Pedagogía del Movimiento, proyecto educativo-político del Movimiento Sin Tierra (MST) en Brasil (Barbosa, 2015, 2016a; Caldart, 2004).

» La Educación Autónoma y el Sistema Educativo Rebelde Autónomo Zapatista de Liberación Nacional (SERAZ-LN), que se vincula al proyecto autónomo del Movimiento Zapatista en México (Barbosa, 2015; 2016b).

» Los Institutos Agroecológicos Latinoamericanos y las escuelas campesinas vinculados a las organizaciones de la CLOC-LVC (Castellano, 2010; Pachón, 2019; Peterle et al., 2017; Val et al., 2019). 
» Las escuelas de formación política de las organizaciones de la CLOCLVC situadas en diferentes países de la región (Rosset et al., 2019).

» Las pedagogías feministas erigidas por los feminismos populares y de la lucha de las mujeres indígenas y campesinas (Anamuri, 2015, Barbosa, 2018; EZLN).

» Las experiencias de las Escuelas Familia Agrícola (EFA) y de la Pedagogía de la Alternancia (Fraga y Sousa, 2017; Moretti et al., 2017).

» La Educación Propia, desarrollada por el movimiento indígena del Cauca (Terreros, 2012).

Desde el punto de vista teórico y metodológico, estos proyectos educativo-políticos buscan, en definitiva, estructurar una concepción de lo educativo y de lo pedagógico basada en los siguientes elementos: ${ }^{1}$

\section{Dimensión epistémica}

\section{El ethos}

En la concepción de lo educativo y de lo pedagógico se reivindica su dimensión epistémica, fundamento del proceso educativo y de formación de una subjetividad política; es la expresión concreta de una racionalidad propia de los sujetos histórico-políticos, la cual se apropia y fortalece en el contexto de su praxis educativo-política. Para muchos movimientos, lo epistémico es lo que le confiere fuerza política, por dotar de sentido el conjunto de las demandas, por ejemplo, aquellas relacionadas con el reconocimiento y la valoración de la identidad (indígena, negra, campesina, etc.), la defensa del territorio y de los comunes, de las lenguas y de las cosmovisiones. Lo epistémico genera un ethos con una potencialidad de creación, en los planes simbólico y concreto, de una identidad vinculada al mundo agrario, de aprehensión del campo como espacio de vida y de una relación con la naturaleza.

En el campo educativo-pedagógico, la matriz epistémica permite a los movimientos problematizar la realidad sociocultural y política desde los referentes de la memoria histórica de la resistencia y la lucha política, así como desde la experiencia y los saberes. Una problematización que hace

1 Desarrollamos estos elementos en el marco de investigaciones realizadas en el Programa Alternativas Pedagógicas y Prospectiva Educativa en América Latina (APPeAL) y en el grupo de investigación Pensamiento Social y Epistemologías del Conocimiento en América Latina y el Caribe (UECE-CNPq), además de mi participación en el Colectivo de Educadores y Educadoras de la Reforma Agraria, impulsado por el Sector de Educación del MST. Estos espacios de formación teórica y política condujeron a la elaboración de algunos referentes que demarcan la naturaleza y las categorías intermedias para el análisis teórico-metodológico de las experiencias educativo-pedagógicas. Para profundizarlas, consultar Gómez-Sollano y Zaslav $(2013 ; 2017)$ y Barbosa $(2013 ; 2016 a)$.

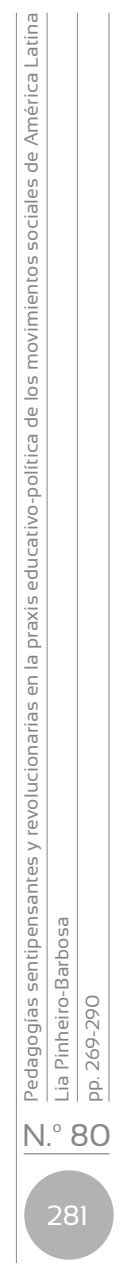


posible conformar horizontes de sentido a las inquietudes que emergen desde este lugar sociocultural, que explicita una relación más intrínseca con los anhelos de la lucha y de la búsqueda cotidiana por cambios más profundos en el ámbito de las relaciones sociales y políticas.

\section{Proyecto ético-político}

Inicialmente, reivindican el derecho a la educación y a la escuela de aquellos a quienes se les negó. Sin embargo, la naturaleza del proyecto ético-político se amplía, al articular el horizonte de las demandas históricas de los movimientos indígenas y campesinos, sobre todo en la defensa del territorio, de los comunes, de la tierra y la reforma agraria, de los derechos humanos, de la autonomía y de las lógicas de la comunalidad, entre otros.

En el ámbito del proyecto ético-político, la intención pedagógica es conformar un sujeto histórico con capacidad de dirección política en la disputa hegemónica, y a la vez crear una praxis política que incida en cambios concretos en la dimensión pública del Estado o en otros niveles de relación con lo institucional, por ejemplo, en el derecho de autodeterminación sobre sus territorios en un plano autonomista.

Hay experiencias que inciden en cambios del marco jurídico-legal, como la institución del Programa Nacional de Educación en la Reforma Agraria y la Política Nacional de la Educación del Campo, articuladas por el MST (Barbosa, 2015, 2016a). Otras incorporan a la agroecología como principio y proyecto político, a propósito de las experiencias de los IALAS de la CLOC-LVC y de la Escuela de Formación Niceto Pérez, de la Asociación Nacional de Agricultores Pequeños (ANAP), en Cuba. Hay aquellas de fortalecimiento del tejido social comunitario y de los procesos de autonomía en sus territorios, como el caso del SERAZ y de la Educación Propia, o aun las que objetivan instaurar un proceso de formación política de las mujeres en el enfrentamiento del patriarcado en los ámbitos endógenos y exógenos a sus organizaciones, conforme las experiencias del IALA para las mujeres del campo Sembradoras de Esperanza, de la Asociación de Mujeres Rurales e Indígenas (Anamuri), en Chile y la Escuela de Formación de Mujeres Líderes Dolores Cacuango, en Ecuador.

\section{Valores}

Los proyectos educativo-políticos de los movimientos indígenas y campesinos poseen principios educativos, pedagógicos y filosóficos, entre ellos: la praxis como principio de la formación humana, el trabajo como principio educativo, el internacionalismo, la organicidad y la colectividad en el vínculo con la comunidad, el antirracismo, el antipatriarcado, la complementariedad entre lo femenino y lo masculino, la cosmovivencia y la espiritualidad, la horizontalidad. En los proyectos político-pedagógicos 
de las escuelas y otros documentos de carácter pedagógico encontramos referencia directa a estos valores y su centralidad en la formación humana auspiciada en el proceso educativo.

\section{Lo procedimental}

\section{Estrategias}

Desarrollan un conjunto de acciones que permiten la existencia de las experiencias educativas mismas, sobre todo en sus territorios, para prevenir el éxodo rural de la juventud, garantizar una educación en el campo y fortalecer los procesos políticos internos en sus comunidades. Hay proyectos educativo-políticos articulados por la vía de la demanda de políticas educativas específicas, conforme a aquellas del MST en Brasil. En este caso, la articulación del sector de educación con los asentamientos, con las universidades públicas y algunos políticos elegidos constituyen una estrategia de presión social y política para materializar, en el ámbito legal, el derecho a tener escuelas del campo en los asentamientos, además de otras garantías, por ejemplo, el transporte escolar para trasladar niños y jóvenes que viven en comunidades del entorno, la merienda escolar, entre otros.

Para las experiencias no institucionales y de carácter autonomista, se desarrollan estrategias de gestión comunal de las escuelas, con mítines para su construcción y la definición de quiénes serán los maestros en la asamblea de la comunidad. En algunos casos, cuentan con la solidaridad de la sociedad civil nacional e internacional para recaudar fondos para la producción de materiales didácticos, para la formación pedagógica de maestros, etcétera.

El currículum constituye un instrumento de incorporación de referentes propios para situar los contenidos de cada área del conocimiento y su transversalidad en el fomento y fortalecimiento de los valores intrínsecos a los principios educativos, pedagógicos y filosóficos.

\section{Saberes}

En las experiencias se identifican diversos saberes que articulan una formación educativa integral y vinculada a proyectos políticos de carácter emancipatorio. Hay saberes de pertenencia, donde los sujetos incorporan matrices de las cosmovisiones y de las lenguas maternas de donde emanan filosofías propias, a ejemplo de la dimensión pedagógica del Popol Wuj (Barbosa, 2019), presente en los materiales didácticos del Seraz. Existen los saberes pedagógicos, reflejados en otras formas de circulación del conocimiento, a propósito de las radios comunitarias, de la milpa, de los 
árboles del saber ${ }^{2}$ y su vínculo con un proceso de mediación pedagógica. Los saberes de integración, que habilitan la recuperación de la memoria histórica, la equidad de género, los derechos humanos y la naturaleza. Asimismo, los saberes socialmente productivos inherentes al trabajo como principio educativo en el fortalecimiento de otras formas de vivir, coexistir y producir en sus territorios. Hay un proceso de construcción de conocimiento mediado por el diálogo de saberes, es decir, en el encuentro entre los saberes de vida y de lucha de los pueblos que se vuelven conceptos elaborados por los movimientos populares y aquellos conocimientos de carácter científico (Barbosa, 2016b; 2017; Tardin, 2006).

\section{Sujetos}

Los sujetos son claves en la sustentación teórica y pedagógica del proyecto educativo-político, es decir, hay un reconocimiento de los sujetos como constructores de conocimiento (Barbosa, 2013; 2015). Hay experiencias en que toda la comunidad constituye un sujeto pedagógico, dedicando tiempo de su trabajo para la producción de alimentos que serán consumidos en la escuela o responsabilizándose por las tareas de los educadores mientras estos están en el aula. En el Seraz, los promotores de educación no reciben un sueldo por su trabajo, por lo tanto, la comunidad asegura una parte de la producción agrícola para ellos y las escuelas autónomas durante el periodo lectivo.

Otras experiencias pretenden crear sujetos histórico-políticos, como las escuelas itinerantes y la formación de los Sin Tierrita, niños de los campamentos y asentamientos del MST (Barbosa y Sales, 2018) o, aun, las escuelas de formación política de mujeres, de jóvenes y de cuadros de la CLOC-LVC (Rosset et al., 2019).

\section{Lo pedagógico}

No se restringe a la dimensión más instrumental de los procesos de enseñanza y aprendizaje en el salón, sea en la escuela o en la universidad. Justo lo contrario, recupera los principios educativos y las metodologías pedagógicas de la Educación Popular y de otros referentes pedagógicos del campo popular. En razón de ello, hay una reterritorialización educativo-pedagógica (Barbosa, 2015; Barbosa y Rosset, 2017) en la cual la praxis educativo-pedagógica incorpora otros lugares para el proceso educativo y formativo, como la milpa, las marchas políticas, los mítines, etc. El proceso de mediación pedagógica da paso a una geopedagogía del conocimiento (Barbosa, 2015), que significa el vínculo indisociable entre

2 En algunas escuelas del campo del MST hay árboles nativos que constituyen locus de una mediación pedagógica de los saberes, por ejemplo, el Maguey del saber. 
lo pedagógico y los elementos culturales que emergen del territorio y del contexto socio-comunitario en la construcción del conocimiento y de su vínculo con los procesos políticos

Pensar procesos educativos y pedagógicos en la óptica de los movimientos indígenas y campesinos significa concebirlos más allá del paradigma de la modernidad occidental, es decir, recuperar el sentido epistémico del acto educativo, concebido desde las epistemes de los pueblos originarios y aquellas epistemes rurales de los campesinos (Barbosa y Rosset, 2017). Una dimensión epistémica que aporta al fortalecimiento de procesos políticos y de otras racionalidades, apoyado en "la re-in-surgencia intelectual pensada y reflexionada desde este centro del pensamiento y saber del pueblo" (López-Intzín, 2013, p. 77), en sintonía con su cosmovisión, con sus banderas de lucha y sus proyectos políticos.

Estas experiencias son ejemplares en la conformación de pedagogías concebidas en procesos históricos, revolucionarios y que visan la emancipación humana. En ellas se fortalecen saberes ancestrales, a la vez que promueven una construcción teórica genuina, desde los movimientos, en un proceso de recuperación y fortalecimiento del sujeto colectivo y de articulación de conceptos clave que advienen de su cosmovisión, de sus lenguas, o aun de procesos histórico-políticos. En la perspectiva de los movimientos indígenas y campesinos, ese proceso de construcción de conocimiento conjuga un movimiento dialéctico entre razón y corazón, es decir, los pensamientos y los saberes pasan por la mente, por la razón, pero también emanan del corazón. Los zapatistas, por ejemplo, dicen que la palabra se corazona. De ahí que las percepciones acerca de la vida y del sernos en el mundo también se orienta desde una lógica enraizada en el Ya'yel-snopel ya'yel-sna'el: sentir-pensar - sentir-saber (López-Intzín, 2013).

Las pedagogías propias de los movimientos indígenas y campesinos ponen en movimiento palabras, conceptos que nacen de la raíz cultural de otras racionalidades, tejidas a lo largo de siglos, por procesos de escucha y escudriñamiento de la lengua, para captar, descifrar, decodificar los códices que son revelados en la convivencia en comunidad, con el fin de alcanzar el Lekil Kuxlejal, el Sumak Kawsai o el Sumak Qamaña. De ahí resulta que las organizaciones que nacen de la base comunitaria indígena y campesina traen consigo un conjunto de conceptos concebidos a la luz de la matriz epistémica de la cosmovisión indígena, de los saberes ancestrales y de las prácticas tradicionales, que fueron negados en el ámbito de la educación formal.

Por siglos, estos referentes siguieron vivos en los cuerpos, la memoria y la oralidad de los pueblos, en su inmersión para reconocerse como oprimidos y subalternizados. Cobran vitalidad en contextos revolucionarios y de resistencia permanente al despojo territorial y a la expropiación de sus identidades. Por lo tanto, los llamé pedagogías sentipensantes y

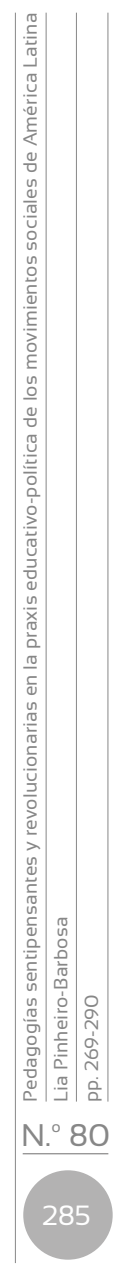


revolucionarias, por su capacidad de creación conceptual enmarcada en otras racionalidades enraizadas en epistemologías y ontologías propias y en diálogo con el legado histórico de las luchas antepasadas. En esas pedagogías sentipensantes, la voz corazonada constituye un puente de diálogo central para articular una perspectiva cosmogónica con el legado teórico y epistémico. Su carácter sentipensante adviene de una interpretación de la realidad social desde la cosmovisión articulada a los marcos de la lucha política. Asimismo, lo comunitario constituye instancia de aprehensión de los principios educativos, en el aprendizaje colectivo de la resistencia, de la lucha, de la autonomía y de la organicidad (Barbosa, 2015).

Las pedagogías sentipensantes y revolucionarias han aportado aprendizajes significativos para la lucha de los pueblos en por lo menos cuatro perspectivas: (1) en la trascendencia de la concepción de lo educativo y de lo pedagógico más allá de la escuela; (2) en la comprensión de que el conocimiento no es atributo exclusivo de una matriz dual, de la razón y de la ciencia, una vez que prescinde también de los sentimientos, de los pensamientos, de la cosmovisión, es decir, el conocimiento en clave pluriversa; (3) en una perspectiva de teorización desde/con/para los movimientos indígenas y campesinos, que les permite consolidar un paradigma epistémico del campo (Barbosa, 2015, 2016b) y en el proceso educativo y formativo de un sujeto histórico-político.

\section{Reflexiones finales}

¿Qué lecciones aportan los movimientos indígenas y campesinos para pensar las pedagogías en el contexto de una praxis política para un devenir emancipatorio? El carácter sentipensante recuperado por Fals-Borda nos permite poner de relieve la vehemencia de un proyecto formativo en el que la concepción de lo educativo y de lo pedagógico recupera la capacidad teórico-política de los movimientos indígenas y campesinos para crear procesos pedagógicos genuinos y articulados a una percepción de los saberes que, en el movimiento dialéctico de la lucha histórica, también poseen referentes que les adjudican la capacidad de concepción de una ciencia propia.

De igual manera, hablo de pedagogías sentipensantes y revolucionarias tomando como referencia la filosofía maya y los procesos revolucionarios latinoamericanos para pensar la praxis pedagógica en la conformación de un sujeto histórico-político y la elaboración teórica que emerge de los movimientos sociales en nuestra historia reciente. En su época, Fals-Borda (2014) Ilamaba la atención sobre la falla histórica en la formación de los niños, quienes no tenían la oportunidad de complejizar su proceso de aprehensión acerca de los sentidos de las palabras, de los conceptos, y eran sometidos a conocerlos en su dicotomía, en palabras del autor, en el blanco-negro. 
En nuestra contemporaneidad, son muchos los movimientos indígenas y campesinos que buscan cambiar ese proceso cognitivo, asumiendo en sus propias manos el quehacer educativo y ocupándose de la formación del sujeto histórico-político, de lo cual la infancia es una parte constitutiva. En esa perspectiva, hay una actitud subversiva en la construcción del conocimiento, enmarcada en el cuestionamiento frontal de las verdades históricas. Así como Fals-Borda (2014) reconocía que las grandes transformaciones latinoamericanas fueron fruto de una conciencia subversiva y un pensamiento rebelde, creo que estamos en un momento fértil para pensar grandes problemas epocales desde los lentes analíticos de los movimientos indígenas y campesinos.

A su vez, al evocar el corazón como lugar de enunciación de un sentipensamiento con raíces epistémicas y ontológicas propias, los movimientos, sobre todo indígenas, plantean otro paradigma de construcción de conocimiento, en que se recupere la unidad entre cuerpo-alma-razón-sentimiento, dimensiones de la existencia humana disociada por la ciencia occidental moderna. Esta unidad es parte constitutiva del sentipensamiento de los pueblos originarios y campesinos y está presente en el caminar histórico de su resistencia política y en la concepción del proceso educativo para un devenir emancipatorio.

En la relación que existe entre educación, resistencia y conocimiento, estos movimientos han aportado teórica y metodológicamente a la elaboración de conceptos que aún no habían sido planteados, como Educación del Campo, soberanía alimentaria, Lekil Kuxlejal, entre otros que reflejan la dialéctica de la descolonización del pensamiento para un devenir de transformación social, de ruptura con el carácter colonial racista, patriarcal y clasista de larga fecha.

Ejemplo de lo anterior es la teoría social desarrollada por el feminismo comunitario en el análisis crítico del entronque patriarcal, es decir, el encuentro del patriarcado ancestral con el de la Conquista, proceso histórico que fortaleció el patriarcado como sistema de opresiones. Este constituye un aporte teórico-político central en la lucha por la despatriarcalización. También existen aquellos "viejos" conceptos que son recuperados desde otras claves analíticas, tal es el caso de la autonomía y la libertad. Son apenas algunos ejemplos de tantos otros conceptos que conforman una teoría de los movimientos sociales y que han sido impulsados por una mediación pedagógica sentipensante.

Finalmente, es central identificar que cada proyecto educativo-político está estructurado desde un marco teórico-metodológico y político, para responder a problemáticas del campo educativo y político. Para ello, se conforma un sujeto pedagógico, se construyen estrategias para hacer realidad la propuesta educativa, además de hacer del proceso educativo 
un acto político y en permanente movimiento, es decir, un movimiento de resistencia histórica de más de cinco siglos en que el horizonte emancipatorio tiene que ver con la dignidad, con la libertad, con el respeto a los derechos humanos y a la equidad de participación entre todas y todos.

\section{Referencias}

Anamuri (2015). Hacia la construcción del feminismo campesino y popular. Boletín El Correo de las Mujeres de Campo. https://es.scribd.com/ document/455216830/Correo-de-las-mujeres-del-campo-AnamuriDic-2015

Barbosa, L. P. (2010). Aproximações reflexivas às experiências latino-americanas campesinas e indígenas em suas interações e lutas sociais em torno das políticas públicas no Brasil e México. Documentos de Trabalho 5. Clacso.

Barbosa, L. P. (2013). Los movimientos sociales como sujetos educativo-políticos. En M. Gómez-Sollano y M. C. Zaslav (orgs.), Reconfiguración de lo educativo en América Latina. Experiencias pedagógicas alternativas (pp. 121-162). UNAM.

Barbosa, L. P. (2015). Educación, resistencia y movimientos sociales: la praxis educativo-política de los Sin Tierra y de los zapatistas. Librunam.

Barbosa, L. P. (2016a). Educação do Campo [Education for and by the countryside] as a political project in the context of the struggle for land in Brazil. Journal of Peasant Studies, 44(1), 1-26.

Barbosa, L. P. (2016b). Educación, conocimiento y resistencia en América Latina: por una teoría desde los movimientos sociales. De Raíz Diversa, 6, 45-79.

Barbosa, L. P. (2017). Movimentos sociais, educação e diálogo de saberes na América Latina. En A. R. Santos y C. P. Nunes (orgs.), Educação e sua diversidade (pp. 259-280). Editus.

Barbosa, L. P. (2018). Mulheres Zapatistas e a pedagogia da palavra no tecer da outra educação. En A. M. Castro y E. C. Machado (orgs.), Estudos feministas, mulheres e educação popular (pp. 25-47). LiberArs.

Barbosa, L. P. (2019). Popol Wuj e a pedagogia maya da milpa. En D. Streck, C. Z. Moretti y T. Adams (orgs.), Fontes da pedagogia latino-americana: heranças (de)coloniais (pp. 23-35). Appris.

Barbosa, L. P y Rosset, P. (2017). Educação do Campo e pedagogia camponesa agroecológica na América Latina: aportes da La Via Campesina e da CLOC. Educação \& Sociedade, 38(140), 705-724.

Barbosa, L. P. y Sales, M. S. (2018). A infância Sem Terra em movimento na luta por escola, terra e dignidade. Temáticas, 26(51), 119-148.

Caldart, R. (2004). Pedagogia do Movimento. Expressão Popular. 
Castellano, M. E. (2010). Instituto Universitario Latinoamericano de Agroecología Paulo Freire. Ministerio del Poder Popular para la Educação Superior.

Cusicanqui, S. R. (1986). Oprimidos pero no vencidos. Hisbol.

Ejército Zapatista de Liberación Nacional (eZLN). (2013). Participación de las mujeres en el gobierno autónomo. [Cuaderno de textos del primer grado del curso La Libertad según [@s Zapatistas].

Escobar, A. (2014). Sentipensar con la tierra. Nuevas lecturas sobre desarrollo, territorio y diferencia. Editora Unaula.

Fals-Borda, O. (2009). Una sociología sentipensante para América Latina. Siglo del Hombre Editores, Clacso.

Fals-Borda, O. (2014). Ciencia, compromiso y cambio social. Antología. El Colectivo-Lanzas y Letras-Extensión Libros.

Fanon, F. (2005). Os condenados da terra. Editora UFJF.

Fanon, F. (2008). Pele negra. Máscaras brancas. EDufBA.

Fraga, R. C. Q. y Sousa, J. R. F. (2017). Pedagogia da Alternância e prática educativa na Educação do Campo: Experiência da Escola Família Agrícola Dom Fragoso no Ceará. Práxis Educacional, 13(26), 196-216.

Freire, P. (1987). Pedagogia do Oprimido. Paz e Terra.

Giacarra, N. (2006). Territorios en disputa: los bienes naturales en el centro de la escena. Realidad Económica, 217, 51-68.

Gómez-Sollano, M. y Zaslav, M. C. (2013). Reconfiguración de lo educativo en América Latina. Experiencias pedagógicas alternativas. México: UNAM.

Gómez-Sollano, M. y Zaslav, M. C. (2017). Saberes, sujetos y alternativas pedagógicas. Contextos, conceptos y experiencias. México: unam.

González-Casanova, P. (1969). Sociología de la explotación. Siglo xxı.

González, M., Burguete, A. y Ortiz-T, P. (2010). La autonomía a debate. Autogobierno indígena y Estado plurinacional en América Latina. Ciesas/Unich.

Gramsci, A. (1968). Literatura e vida nacional. Editora Civilização Brasileira.

Gramsci, A. (1975). Cuaderni dei Carcere. Einaudi, Edizione critica dell'Instituto Gramsci.

Gutiérrez-Aguilar, R. (2008) Los ritmos del Pachakuti: movilización y levantamiento indígena-popular en Bolivia (2000-2005). Tinta Limón.

Lenkersdorf, C. (2005). Los hombres verdaderos. Voces y testimonios tojolabales. Siglo xxı.

López-Intzín, X. (2013). Ich'el ta muk': la trama en la construcción del Lekil Kuxlejal (vida plena-digna-justa). En Torres-Méndez, G.; López-Intzín, X.; Marcos, S. y Osorio-Hernández, C. (coords.). Senti-pensar el género. Perspectivas desde los pueblos originarios (pp. 73-106). Red-IINPIM/Red Feministas Decoloniales. 
Mariátegui, J. C. (1928). Siete ensayos de interpretación de la realidad peruana. ERA.

Martínez-Torres, M. E. y P. M. Rosset. (2013). Del conflicto de modelos para el mundo rural emerge la vía campesina como movimiento social transnacional. El Otro Derecho, 44, 21-57.

Moretti, C. Z.; Vergutz, C. L. B. y Costa, J. P. R. (2017). "Chama a Roda" na Escola Família Agrícola de Santa Cruz do Sul: o círculo de cultura reiventado na Pedagogia da Alternância. Práxis Educacional, 13(26), 217-235.

Pachón, F. (2019). IALAs: la Universidad Campesina de América Latina. Biodiversidad. Sustento y Culturas, 102, 9-13.

Peterle, R., Greco, M. L. y Martín, F. (2017). Construyendo pedagogías emancipatorias: la Escuela Campesina de Agroecología-Mendoza, Argentina. Práxis Educacional, 13(26), 236-251.

Porto-Gonçalves, C. W. (2009). Entre América e Abya Yala - tensões de territorialidades. Desenvolvimento e Meio Ambiente, 20, 25-30.

Rosset, P. (2015). Epistemes rurales y la formación agroecológica en La Vía Campesina. Ciencia y Tecnología Social, 2, 1-10.

Rosset, P., Val, V., Barbosa, L. P. y McCune, N. (2019). Agroecology and La Via Campesina II. Peasant agroecology schools and the formation of a sociohistorical and political subject. Agroecology and Sustainable Food Systems, 43(7-8), 895-914.

Silva, V. I. (2014). Classe camponesa: modo de ser, de viver e de produzir. Padre Jósimo.

Svampa, M. y Antonelli, M. (2009). Minería transnacional, narrativas del desarrollo y resistencias sociales. Biblos.

Tapia, L. (2006). La invención del núcleo común. Ciudadanía y gobierno multisocietal. Cides-UMSA/ Posgrado de Ciencias del Desarrollo.

Tardin, J. M (2006). Diálogo de Saberes no Encontro de Culturas: Sistematização (mimeo). 2.

Terreros, M. I. G. (2012). La educación propia: entre legados católicos y reivindicaciones étnicas. Pedagogía y Saberes, 36, 33-43.

Torres-Méndez, G. (2013). Mujeres Mayas-Kichwas en la apuesta por la descolonización de los pensamientos y corazones. En G. Torres-Méndez, X. López-Intzín, S. Marcos y C. Osorio-Hernández, (coords.), Senti-pensar el género. Perspectivas desde los pueblos originarios (pp. 27-61). Red-IINPIM/Red Feministas Decoloniales.

Val, V., Rosset, P. M., Zamora-Lomelí, C., Giraldo, O. F. y Rocheleau, D. (2019). Agroecology and La Via Campesina ı. The symbolic and material construction of agroecology through the dispositive of "peasant-to-peasant" processes. Agroecology and Sustainable Food Systems, 43(7-8), 872-894. 